\title{
Níveis de concentração e concorrência dos bancos brasileiros e seus conglomerados: de Tombini a Goldfajn
}

\author{
Edson Roberto Vieira ${ }^{1}$ \\ Antônio Marcos de Queiroz ${ }^{2}$ \\ Cleidinaldo de Jesus Barbosa ${ }^{3}$ \\ Danilo Pereira de Souza Moura ${ }^{4}$
}

\section{RESUMO}

O objetivo desse trabalho é avaliar a evolução da concentração bancária no país no período 2010-2017 e verificar as característica da indústria bancária no Brasil em relação à concorrência, por meio do modelo de Panzar \& Rosse. Foram realizadas análises dos bancos por unidade de negócio (CNPJ) e também dos conglomerados do sistema financeiro nacional. O modelo foi aplicado sobre os dados dos dois diferentes períodos da liderança do Banco Central entre os anos de 2010 a 2017: primeiramente sobre a gestão de Alexandre Tombini e logo em seguida sobre a gestão de Ilan Goldfajn. O método utilizado para realização das estimações foi o Feaseble Generalized Least Squares $F G L S$. As análises realizadas sugeriram haver significativa concentração bancária no país e intensificação desse quadro no recorte temporal estudado. Já a aplicação do modelo Panzar \& Rosse indicou a ocorrência de forte poder de mercado no setor bancário doméstico, embora a análise por período tenha dado indícios de melhora da concorrência entre 2016 e 2017.

Palavras chave: Concentração bancária, concorrência bancária, política monetária, modelo Panzar \& Rosse.

\section{Concentration and competition levels of Brazilian banks and their conglomerates: from Tombini to Goldfajn}

\begin{abstract}
The objective of this study is to evaluate the evolution of bank concentration in the country in the period 2010-2017 and to verify the characteristics of competition in the banking industry in Brazil, using the Panzar \& Rosse model. Analyzes were made of the banks by business unit and also of the financial conglomerates of the Brazilian financial system. The model was applied on data from the two different periods of the Central Bank leadership between 2010 and 2017: first on the management of Alexander Tombini and then on the management of Ilan Goldfajn. The method used to make the estimates was Feaseble Generalized Least Squares (FGLS). The analyzes suggested that there is a significant banking concentration in the country and an intensification of this scenario in the period studied. The application of the Panzar \& Rosse model indicated strong market power in the domestic banking sector, although the analysis by period showed signs of improved competition between 2016 and 2017.
\end{abstract}

Key words: Banking concentration, banking competition, monetary policy, Panzar \& Rosse model.

\section{INTRODUÇÃO}

A relação entre concentração e competição não é tão direta quanto parece ser. Embora a concentração também possa facilitar a redução da competição, um mercado pode ser concentrado e o comportamento dos bancos competitivo. Além disso, a concentração de mercado pode não

\footnotetext{
${ }^{1}$ Professor Adjunto da Faculdade de Administração, Ciências Contábeis e Ciências Econômicas - FACE/UFG. Contato: edson_vieira@ufg.br

2 Professor Adjunto da Faculdade de Administração, Ciências Contábeis e Ciências Econômicas - FACE/UFG. Contato: antonio_marcos_queiroz@ufg.br.

${ }^{3}$ Professor Adjunto da Faculdade de Administração, Ciências Contábeis e Ciências Econômicas - FACE/UFG. Contato: cleidinaldo@ufg.br.

${ }^{4}$ Bacharel em Economia pela Faculdade de Administração, Ciências Contábeis e Ciências Econômicas - FACE da Universidade Federal de Goiás - UFG. Contato: danilopsmlg@gmail.com.
} 
significar que haja um poder de mercado prejudicial, podendo ser resultado de uma eficiência maior daqueles bancos que detém uma maior parcela do mercado (NUNES; MENEZES; DIAS, 2013). Por sua vez, a reputação que os grandes bancos adquirem junto aos seus clientes pode imprimir maior estabilidade ao sistema e contribuir para que estas instituições aumentem ainda mais seu market share (CARVALHO, 2007).

A questão é que as análises clássicas da microeconomia em termos de concentração de mercado nem sempre podem ser aplicadas da mesma maneira sobre o mercado bancário. A redução da concentração poderia ter origem, por exemplo, na entrada de novos bancos no mercado, mas isso acaba sendo dificultado pela própria regulação do setor. A necessidade de forte regulação é justificada pelo risco sistêmico, tendo em vista a magnitude dos problemas econômicos e sociais que uma crise bancária pode provocar, não apenas para o país, como também em escala global ${ }^{5}$. Além disso, o problema do risco moral pode sugerir que um setor bancário concentrado seja preferível a um menos concentrado. Argumenta-se que a maior concorrência pode induzir os bancos a tomarem maiores riscos na oferta de crédito e diminuir a confiança no sistema (SILVEIRA, 2017; CARDOSO, 2011).

A despeito dessas considerações, os indicadores do setor bancário brasileiro são intrigantes. Em meio à grave crise econômica que atingiu o país, o lucro consolidado dos quatro maiores bancos brasileiros com ações em bolsa ${ }^{6}$ atingiu, no $2^{\circ}$ trimestre de 2015 , o maior patamar ( $\mathrm{R} \$ 17,34$ bilhões) da base de dados da consultoria Economática, iniciada em 2006. E, mesmo com a queda da taxa básica de juros da economia doméstica, Selic, que teve lugar a partir de outubro/2016, o lucro líquido deste grupo somou R\$ 16,88 bilhões no $2^{\circ}$ trimestre de 2018 , obtendo o segundo lugar na série histórica da Economática (LUCRO ..., 2018).

Não por acaso, frequentemente, os juros praticados pelo setor bancário brasileiro são atribuídos à concentração desse setor. Mas este tipo de avaliação não é gratuito. A participação do mercado bancário brasileiro é concentrada em um grupo seleto de instituições. Os cinco maiores bancos do país detinham, em média, cerca de 77,0\% das operações de crédito, 72,5\% dos depósitos a prazo e 70,0\% dos ativos totais do setor no período 2010-2017 ${ }^{7}$. Quando a análise é feita por conglomerados financeiros, a concentração diminui no caso dos depósitos a prazo $(51,0 \%)$, mas se intensifica no tocante ao total das operações de crédito $(83,0 \%)$ e aos ativos totais $(80,0 \%)^{8}$.

Investigações feitas em setores com as especificidades da indústria bancária requerem métodos distintos para se analisar a concentração e a concorrência. Assim, além de avaliar a concentração bancária no país no período entre 2010 e 2017, objetiva-se neste trabalho verificar qual é a característica da concorrência na indústria bancária do Brasil, por meio do modelo de Panzar \& Rosse e de sua resultante estatística $H$. O método utilizado para realização das estimações foi o Feaseble Generalized Least Squares - FGLS, que foi aplicado sobre os dados dos bancos por unidade de negócio (CNPJ) e sobre os dos conglomerados financeiros que atuam no país.

Um dos principais motivadores da retomada do tema abordado neste trabalho no período recente é o fato de a taxa básica de juros do país ter apresentado quedas significativas, que não necessariamente foram acompanhadas por reduções das taxas praticadas nos empréstimos concedidos pelos bancos que atuam no mercado doméstico. Nesta linha, um diferencial deste estudo é que ele foi realizado com dados dos dois diferentes períodos da liderança do Banco Central entre os anos de 2010 e 2017: primeiramente sobre a gestão de Alexandre Tombini e, logo em seguida, sob a gestão de Ilan Goldfajn.

\footnotetext{
${ }^{5}$ Segundo Cardoso (2011), o risco de uma crise bancária pode ser comparado à falência de uma empresa do setor petrolífero, que apresenta impactos diretos sobre todos os setores da economia, uma vez que interfere diretamente no fornecimento de produtos essenciais à atividade econômica. Cardoso (2011) registra ainda que uma crise bancária com efeitos de corrida aos bancos por saques (ou seja, uma retirada em massa dos recursos aplicados em depósitos à vista) poderia ter impacto ainda maior, atingindo até mesmo empresas com ótima saúde financeira.

${ }^{6}$ Itaú, Bradesco, Santander e Banco do Brasil.

${ }^{7}$ Vide Tabelas 1, 2 e 3 da seção 4.1.1.

${ }^{8}$ Vide Tabelas 5, 6 e 7 da seção 4.1.2.
} 
O trabalho foi dividido em cinco seções, levando-se em conta esta introdução e as considerações finais. A segunda delas contém a revisão bibliográfica, na qual buscou-se apresentar os principais trabalhos que também discutem o tema enfocado neste trabalho; na terceira seção, tem-se destacados os dados, o modelo econométrico, além da metodologia utilizada para calcular os índices de concentração, concorrência e para estimar os modelos; e a quarta seção apresenta os resultados encontrados e as discussões provocadas pelo trabalho.

\section{REVISÃO BIBLIOGRÁFICA}

\subsection{Fases da Política Monetária, Crédito e Taxas de Juros no Brasil no Período 2010-2017}

No período analisado neste trabalho (2010-2017), podem ser destacadas três importantes fases da política monetária no Brasil, que parecem ter influenciado os lucros e aumentado a concentração bancária no país. A primeira delas teve início em outubro de 2011, quando o Comitê de Política Monetária - COPOM deu a arrancada para a redução da taxa básica de juros, Selic, alçando-a a baixas históricas até então não vistas no pós-Plano Real, no bojo da chamada "Nova Matriz Econômica" 9 , adotada pela equipe econômica do Governo da Presidente Dilma Rousseff.

A segunda fase dessa política marcou o início do movimento contrário nos níveis da Selic, quando essa taxa começou a ser elevada novamente, a partir de maio de 2013, no âmbito dos movimentos do Banco Central (BC) para tentar recolocar a inflação dentro da meta estabelecida pelo Conselho Monetário Nacional - CMN. Já a terceira fase foi iniciada com a mudança do Presidente do BC, em decorrência do último processo de Impeachment presidencial ocorrido no país, quando teve lugar a adoção de uma política monetária ortodoxa tradicional.

Na primeira fase da política monetária brasileira supracitada, a meta da taxa básica de juros da economia foi sendo rebaixada pelo COPOM, até chegar no nível histórico de 7,25\% ao ano (a.a.) entre novembro/2012 e abril/2013, mesmo com a inflação acima da meta estabelecida pelo CMN em 30 de junho de 2009, de 4,5\% a.a (FIGURA 1). Neste período, o BC era dirigido por Alexandre Tombini (desde janeiro de 2011) e a equipe econômica do Governo havia anunciado a entrada em vigor da "Nova Matriz Econômica".

Segundo o Ministro da Fazenda, Guido Mantega, tal Matriz promoveria mudanças estruturais em pontos-chave da economia brasileira, como o ajuste das taxas de juros para níveis mais baixos e uma desvalorização da moeda brasileira com o objetivo de incentivar as exportações (MANTEGA, 2012). Previa-se também a adoção de alguns programas incentivadores de investimento, tais como o Programa Sustentação do Investimento - PSI, no âmbito do qual as taxas de juros eram de $2,5 \%$ a.a., ou seja, abaixo da própria Selic, que naquele período tinha atingido a mínima de $7,25 \%$ a. a. ${ }^{10}$

\footnotetext{
${ }^{9}$ A Nova Matriz Econômica diz respeito ao conjunto de medidas adotado no governo da Presidente Dilma Roussef para estimular o crescimento econômico e os investimentos no país. Segundo o então secretário de política econômica do Ministério da Fazenda, Márcio Holland, buscava-se ter no país uma taxa de câmbio competitiva, redução dos tributos e, principalmente, a redução da taxa Selic (GOVERNO..., 2013).

${ }^{10} \mathrm{O}$ programa possuía ainda a participação do Banco Nacional de Desenvolvimento Econômico e Social - BNDES, que, segundo Mantega (2012), liberaria em empréstimos o montante de R\$ 85 bilhões no ano de 2013. Mantega (2012) afirmava na época que seriam liberados ainda $\mathrm{R} \$ 15$ bilhões dos depósitos compulsórios retidos pelo Banco Central, sendo que esses recursos seriam somados ao montante gerido pelo BNDES e disponibilizados para as empresas tomarem empréstimos aos juros de $2,5 \%$ a.a.
} 
Figura 1: IPCA a.a X SELIC a.a (jan/2010 - dez/2017)

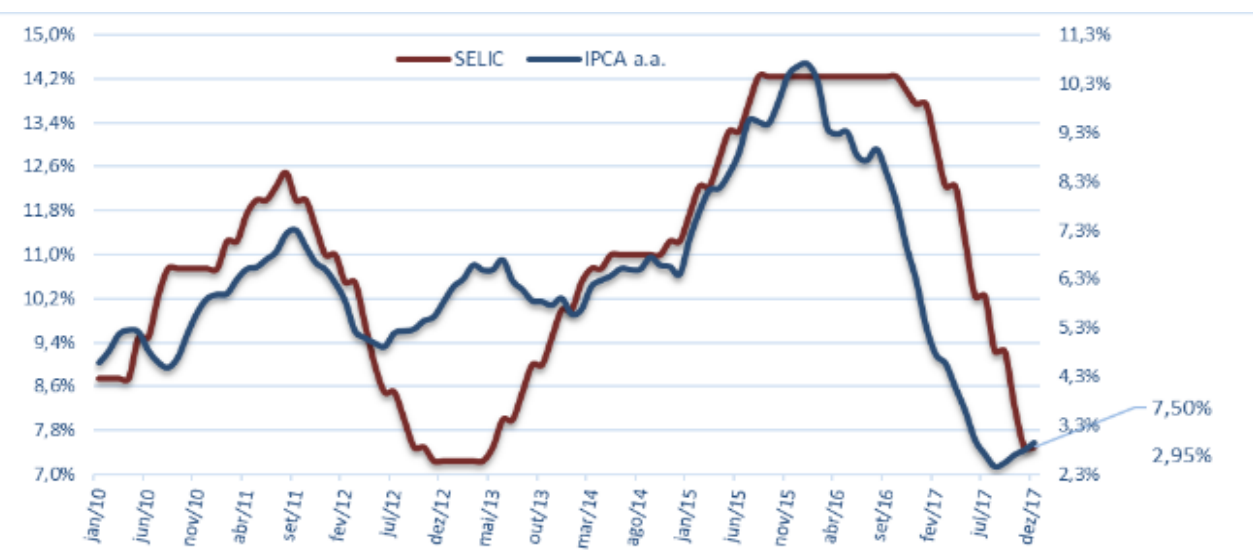

Fonte: Elaboração própria a partir de dados do IBGE e do Banco Central.

A inflação voltou a subir (FIGURA 1) e, com sua escalada, o BC de Tombini passou a adotar uma postura mais rígida. Além das altas na Selic, o BC buscou diminuir a liquidez no mercado financeiro, operando no mercado de reservas por meio de pequenas alterações nas regras dos depósitos compulsórios. Uma das mudanças observadas no período foi estabelecida pela Circular $n^{\circ} 3.360$ da autoridade monetária, que definiu a antecipação do fim do incentivo concedido aos grandes bancos, que podiam se utilizar de recursos dos depósitos compulsórios para comprarem carteiras de crédito de bancos pequenos.

A segunda fase da política monetária brasileira teve início justamente a partir de maio/2013, quando o COPOM decidiu elevar novamente a Selic, de modo a tentar fazer com que a taxa de inflação convergisse para a meta estabelecida. Inicialmente, o processo surtiu efeito e a inflação caiu de 6,5\% a.a., em maio/2013, para 5,59\% a.a., em janeiro/2014. Entretanto, naquele ano, o país entrou em um período de recessão e num processo de altas de alguns preços importantes para a composição dos índices de preços, que culminou numa inflação que atingiu o pico histórico de $10,71 \%$ em janeiro/2016 (FIGURA 1) ${ }^{11}$.

Naquele período, o Governo da Presidente Dilma já estava prestes a entrar em um processo que poderia cassar seu mandato e o gestor do $\mathrm{BC}$ vinha acumulando má reputação, uma vez que não conseguia controlar a inflação e era acusado de não ter independência para operacionalizar este controle. Foi neste contexto que novas medidas foram tomadas pelo BC para tentar reduzir a inflação, sendo que a principal delas era a elevação da Selic em 7 pontos percentuais. Contudo, ao final do ano de 2015, havia sido iniciada a análise do Impeachment da Presidente Dilma Rousseff e, já com poderes de Chefe de Estado, o então Vice-Presidente, Michel Temer, iniciou uma série de mudanças de equipes nos ministérios. Uma delas foi a indicação de Henrique Meirelles para o Ministério da Fazenda, o qual, por sua vez, alçou a Presidente do Banco Central, o economista Ilan Goldfajn, que assumiu o posto em 9 de junho de 2016.

$11 \mathrm{Na}$ Carta Aberta enviada ao Ministro da Fazenda (Aviso 1/2016-BCB: <http://www.bcb.gov.br/htms/relinf/carta2016.pdf >), o então presidente do BC, Alexandre Tombini, explicou os motivos que levaram ao estouro do limite superior da faixa de tolerância da meta de inflação de $2 \%$ acima da meta de 4,5\%. Tombini defendia que a inflação havia sofrido um forte impacto dos preços administrados vis-à-vis o nível dos preços livres e citava o realinhamento dos preços domésticos dos combustíveis com os preços internacionais. Neste período, iniciava-se o segundo mandato da presidente Dilma Rousseff e o Governo Federal havia assumido uma nova postura em relação aos preços administrados e, com isso, os preços dos combustíveis sofreram variação positiva, assim como as tarifas da energia elétrica, que também foram reajustadas. Os reajustes nos preços dos combustíveis tiveram impacto direto nos contratos de transporte público, que também foram corrigidos. Ademais, todos esses segmentos, em especial o dos transportes, sofreram fortemente com a depreciação cambial que ocorreu naquele ano, com forte impacto no Índice Nacional de Preços ao Consumidor Amplo - IPCA. Outro fator que influenciou diretamente na inflação no ano de 2015 foi o segmento de alimentos e bebidas, que teve naquele ano uma variação positiva acumulada de $12,01 \%$ em relação ao ano anterior. 
A partir da entrada Goldfajn no BC, teve lugar a $3^{\mathrm{a}}$ fase da política monetária brasileira no período analisado neste trabalho. Houve o abandono da "Nova Matriz Econômica" e a aplicação de uma política monetária ortodoxa tradicional, no bojo do sistema de metas de inflação. No mês de junho/2016, a inflação já havia iniciado sua trajetória de queda, porém, ainda estava ao nível de $8,84 \%$ a.a (FIGURA 1 ).

Dessa forma, o COPOM optou pela manutenção da Selic em 14,25\% a.a. e, além dessa medida, foram mantidas as políticas em relação aos depósitos compulsórios. Somente a partir de outubro/2016, o COPOM passou a iniciar o novo ciclo de queda da Selic, encerrando o ano de 2017 no nível de 7,50\% a.a. Este novo ciclo de rebaixamento da Selic durante a gestão de Ilan Goldfajn foi justificado pela forte queda da inflação brasileira. Desde a entrada do novo presidente na autoridade monetária, o IPCA, caiu dos 8,84\%, em junho/2016 para 2,95\% ao final de 2017 (FIGURA 1). ${ }^{12}$

Isto posto, as atenções começaram a se voltar para a oferta de crédito no Brasil e seu custo para os tomadores finais. Com a Selic em níveis historicamente baixos, juntamente com uma inflação em patamares mais comportados, esperava-se que essa situação remetesse os bancos brasileiros ao aumento dos empréstimos e também à queda nas taxas de juros que praticavam. Entretanto, não foi isso que se observou: mesmo com o país vivendo uma das suas piores crises, o setor bancário seguiu praticando altas taxas de juros, sem ampliar a oferta de crédito e mantendo alta rentabilidade ${ }^{13}$. Belaisch (2003) observa que a oferta de crédito no Brasil é pequena, especialmente quando comparada à de países mais desenvolvidos. Nos últimos anos, embora pareça ter ensaiado certa recuperação a partir da metade de 2017, as concessões de crédito na economia brasileira não voltaram ao pico atingido no final de 2014. Com a crise que assolou a economia doméstica desde então, observou-se uma tendência de queda nas de crédito do país, atingindo tanto para pessoas físicas (PF), quanto para pessoas jurídicas (PJ) (FIGURA 2).

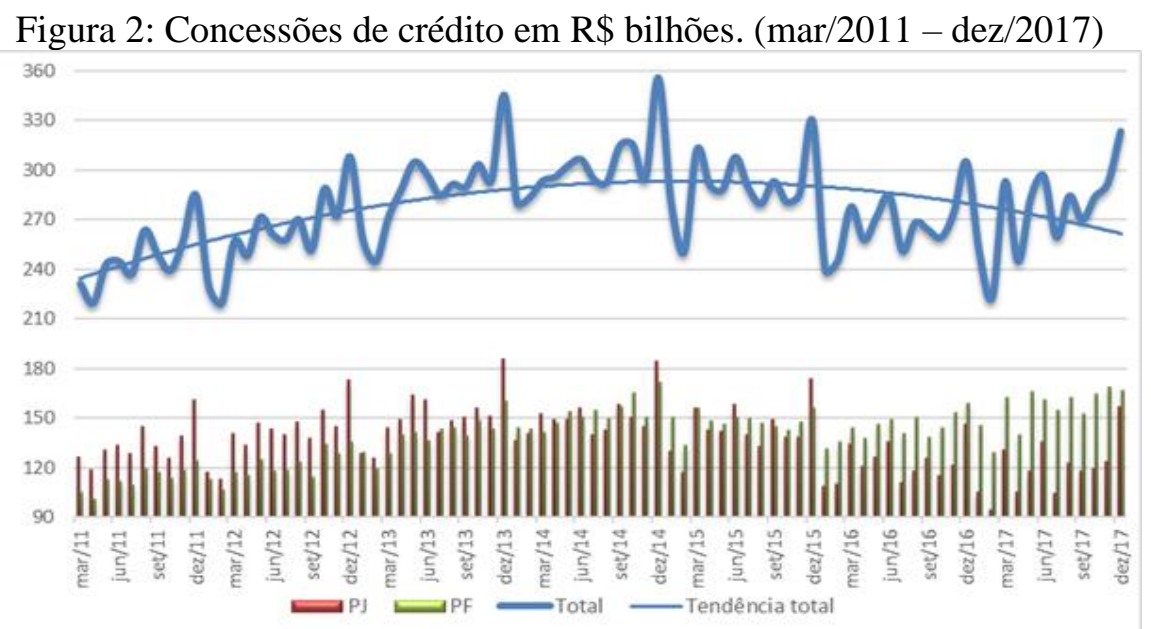

Fonte: Elaboração própria a partir de dados do IBGE.

\footnotetext{
12 Por conta da queda da inflação no ano de 2017, tal como ocorrido com Tombini em 2015, o Presidente do BC teve de explicar ao Ministro da Fazenda, por meio de uma Carta Aberta (Aviso 02/2018 - BCB: https://www.bcb.gov.br/htms/relinf/carta2018.pdf), os motivos que levaram a inflação a ficar abaixo do limite inferior do intervalo de tolerância de $1,5 \%$ da meta de 4,5\%, no bojo de um processo de grande queda dos níveis de emprego e renda do país. Na carta, Goldfajn chamou a atenção para a queda dos preços da alimentação a domicílio e sua importante contribuição para a queda do IPCA em relação ao ano anterior. Destacou que, no ano de 2017, o país viveu uma safra recorde e, com isso, teve-se um choque positivo do lado da oferta, proporcionando preços menores aos alimentos. Além disso, com a crise pela qual o país passava, a taxa de desemprego alcançou níveis elevados e o poder de consumo da população caiu fortemente, de forma que a demanda em declínio dificultava o aumento dos preços pelas empresas.

${ }^{13}$ Como já mencionado acima, o lucro consolidado dos quatro maiores bancos brasileiros com ações em bolsa atingiu recordes no $2^{\circ}$ trimestre de 2015 e no $2^{\circ}$ trimestre de 2018, atingindo $\mathrm{R} \$ 17,34$ bilhões e R\$ 16,88 bilhões, respectivamente nestes períodos.
} 
No que tange ao custo dos empréstimos, a Figura 3 mostra que as taxas de juros domésticas caíram a partir da redução da Selic. Todavia, este movimento se mostrou lento, especialmente quando aquela taxa caiu de forma mais intensa. Foi o que se observou nas duas grandes quedas da Selic no período que compreende agosto/2011 e maio/2013 e no período mais recente, que se iniciou no segundo semestre de 2016.

Figura 3: Taxas médias de juros cobradas nas operações de crédito a.a. vs. Taxa Selic a.a (mar/2011- dez/2017)

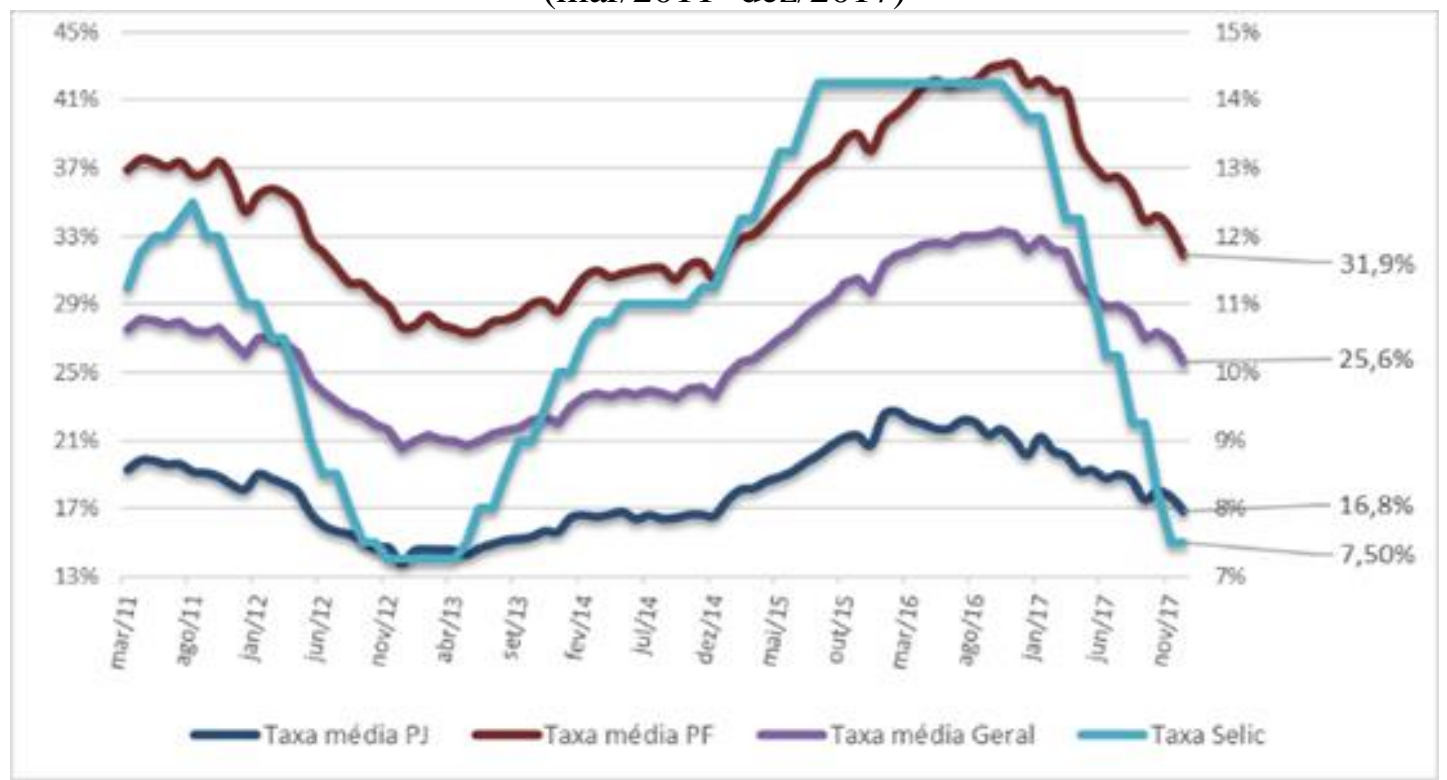

Fonte: Elaboração própria a partir de dados do IBGE.

Figura 4: Taxas médias de juros para recursos direcionados a.a. vs. Taxa Selic a.a. (mar/2011 $\operatorname{dez} / 2017)$

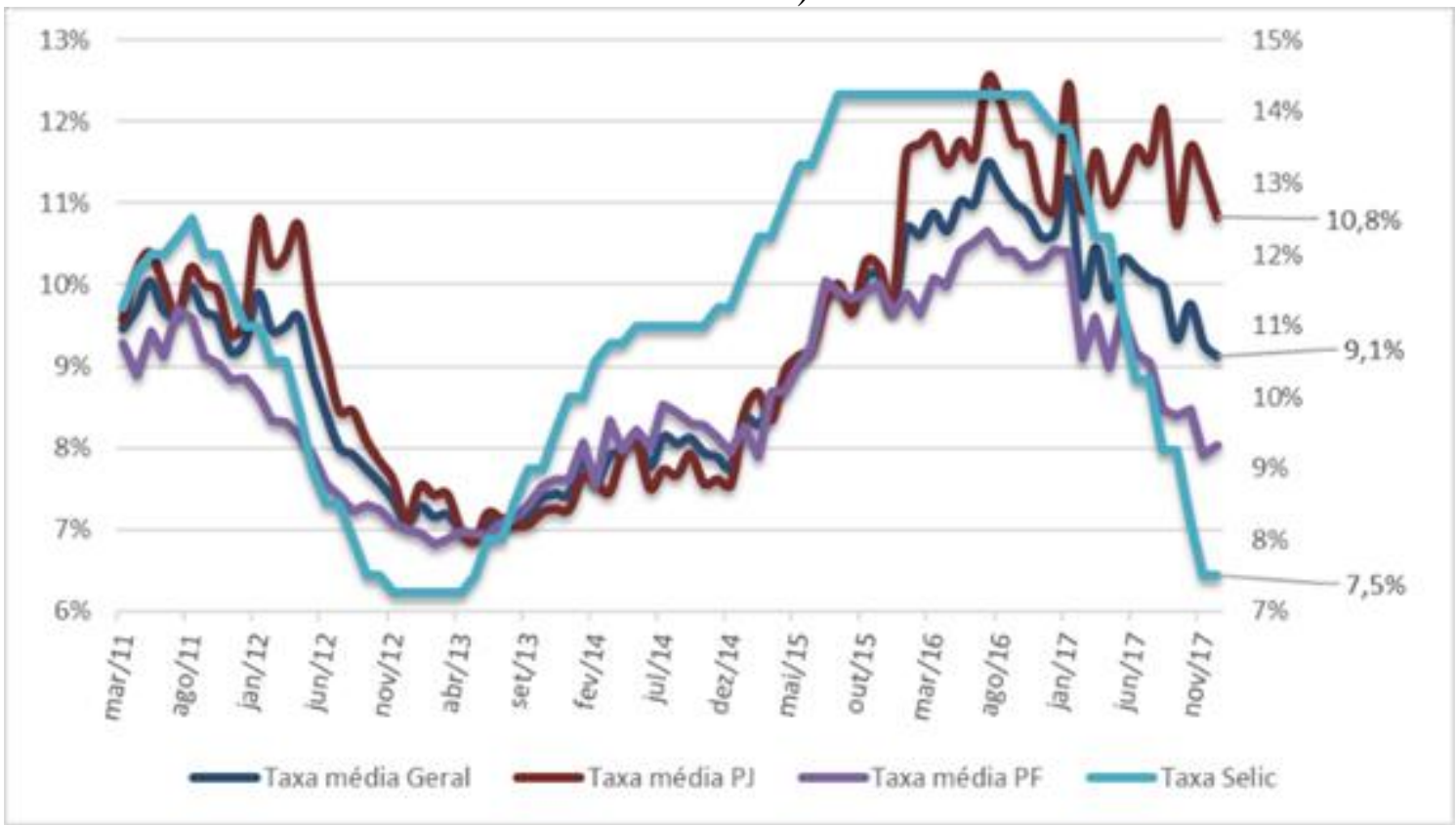

Fonte: Elaboração própria a partir de dados do IBGE. 
Para uma melhor avaliação deste processo, faz-se necessária a separação das taxas de juros cobradas de empréstimos realizados com recursos direcionados e com recursos livres ${ }^{14}$. Pelo a Figura 4, observa-se que, mesmo para os recursos direcionados, a evolução das taxas de juros cobradas pelas operações de crédito possui uma defasagem em relação às movimentações da Selic. Por sua vez, quando comparado com as taxas de juros para recursos livres, as taxas para créditos direcionados acompanham a taxa básica de modo mais rápido. E, como a Figura 5 deixa claro, a diferença é expressiva entre as taxas cobradas nas concessões de crédito livre e a taxa de juros básica da economia.

Figura 5: Taxas médias de juros para recursos livres a.a. vs. Taxa Selic a.a. (mar/2011 - dez/2017)

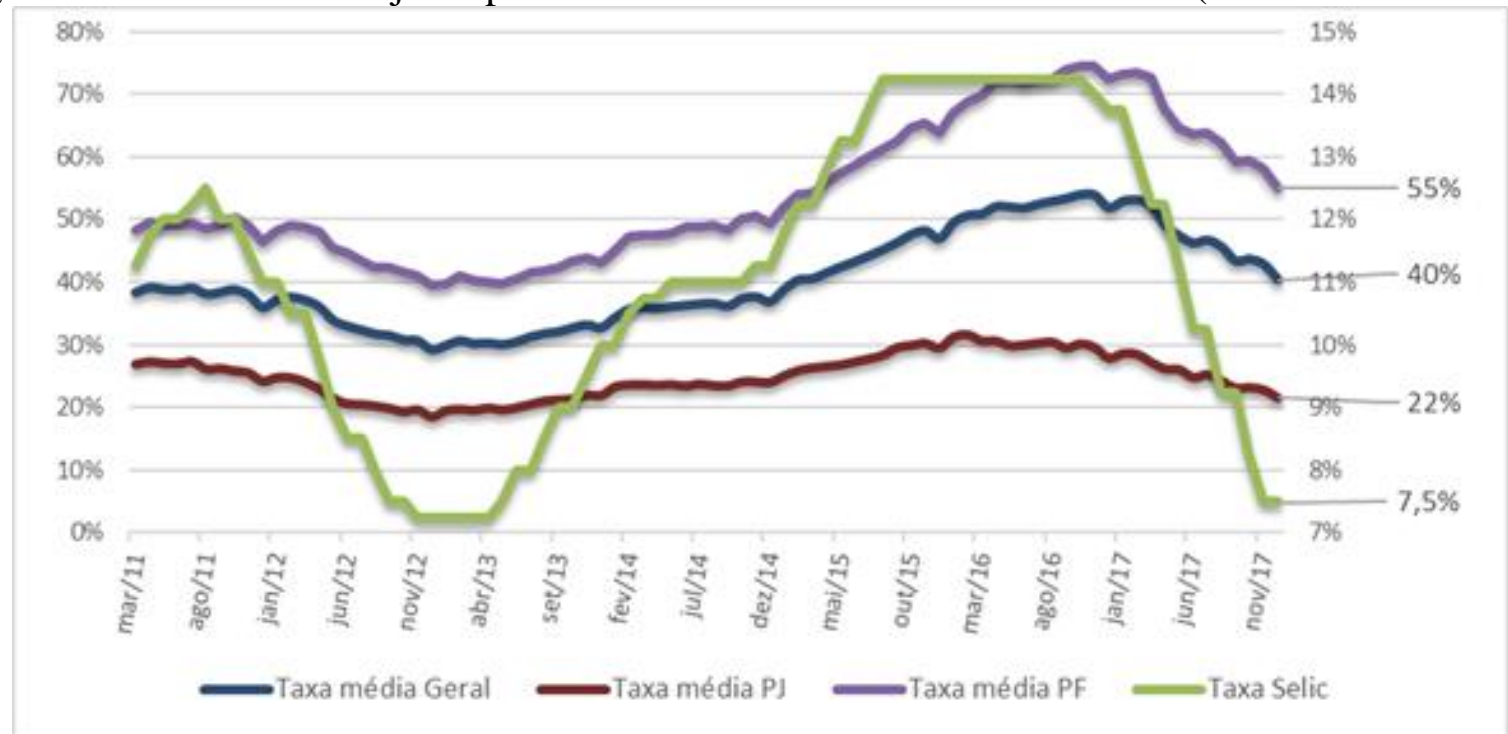

Fonte: Elaboração própria a partir de dados do IBGE.

Figura 6: Evolução do Spread bancário sobre recursos livres por tomador em p.p. vs a Taxa Selic a.a. (mar/2011 - dez/2017)

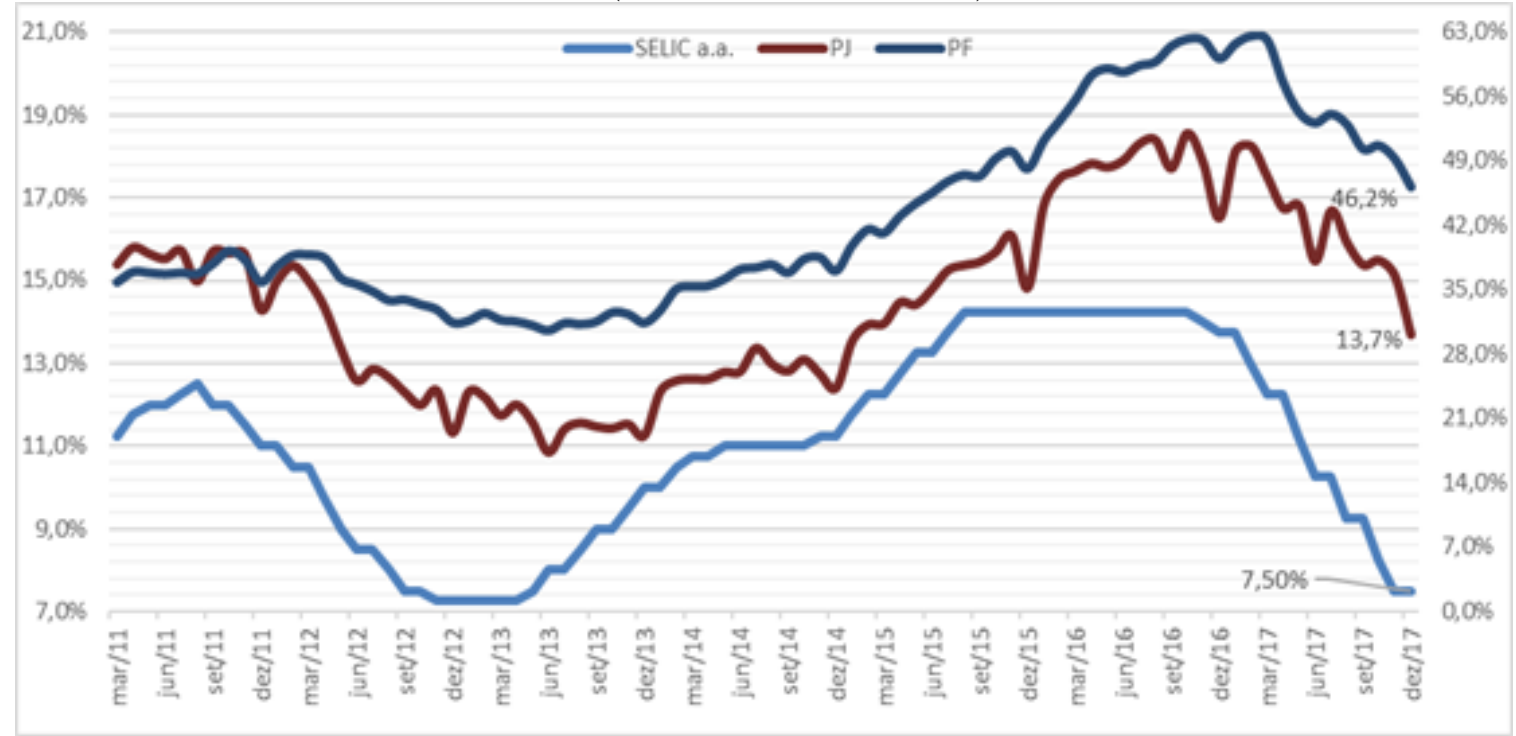

Fonte: Elaboração própria a partir de dados do IBGE.

\footnotetext{
${ }^{14}$ Os créditos direcionados são aqueles destinados a determinados setores ou atividades, realizados com recursos regulados em lei ou normativo, sendo, em sua maioria, controlados pelos bancos oficiais, ou seja, os bancos públicos de controle do governo. Já os recursos livres compõem todo o restante do volume de crédito disponível na economia.
} 
Evidentemente, todas essas análises ficam incompletas sem o exame do spread bancário, que é calculado de modo a representar a diferença entre as taxas de juros das operações de crédito ofertadas pelos bancos e a remuneração paga aos depositantes que disponibilizam o recurso que compõe o montante emprestado. A Figura 6 mostra a evolução do spread bancário no Brasil nos últimos anos para as concessões de crédito para pessoas físicas e jurídicas contra a evolução da Selic. Ao analisar a evolução do spread no mercado bancário brasileiro nos últimos anos, observa-se uma forte tendência de alta. E, quando se confronta a evolução do volume de operações de concessão de crédito com as taxas de juros cobradas dos tomadores de empréstimo, tem-se no nível do spread uma possível explicação para a elevada rentabilidade dos bancos no país.

Tudo isso reacendeu os debates quanto à concorrência e concentração no mercado bancário brasileiro. Embora apresentem conclusões distintas em relação aos níveis de competição que vigoram no setor, os principais estudos anteriores concordam que a indústria bancária brasileira é altamente concentrada e que este processo foi se intensificando ao longo dos anos, mesmo quando sob diferentes óticas, tais como os mercados de crédito, os níveis de depósitos e também os ativos bancários. Vejamos na revisão bibliográfica apresentada na próxima seção.

\subsection{Trabalhos empíricos que utilizam o modelo Panzar \& Rosse}

O método de Panzar \& Rosse (1987) é bastante utilizado para analisar o grau de competitividade do setor bancário. Tal método assume que os bancos operam num equilíbrio de longo prazo e que seu desempenho é influenciado pelas ações de outros bancos no mercado, aferindo seu comportamento competitivo com base nas propriedades comparativas estáticas de uma equação de receita na forma reduzida (BIKKER; HAAF, 2002). Com isso, busca-se estimar a estatística $\mathrm{H}$, que, em resumo, é a soma das elasticidades da receita em relação aos custos e preços dos insumos, definindo, assim, o grau do poder de mercado dos bancos. A estimação desta estatística visa classificar o mercado pelo tipo de concorrência. A soma das elasticidades que define um mercado monopolista deverá ser menor que zero (ou seja, $\mathrm{H} \leq 0)$ ), igual a $1(\mathrm{H}=1)$ para o mercado em concorrência perfeita e entre zero e $1(0<\mathrm{H}<1)$ se a estrutura do mercado for de concorrência monopolística.

Um dos trabalhos mais citados que utilizaram o modelo de Panzar \& Rosse (1987) para analisar o setor bancário brasileiro é o de Belaisch (2003). Por meio da estimação por dados em painel com efeitos fixos e aleatórios, a autora avaliou este setor com uma amostra de 49 bancos no período 1997-2000, obtendo resultados que rejeitam as hipóteses de comportamento perfeitamente competitivo e concluindo que os bancos brasileiros tinham no período um comportamento de concorrência monopolística. Além disto, a autora concluiu que os bancos brasileiros eram, na época, altamente rentáveis, porém menos eficientes, quando comparados com bancos de países desenvolvidos, como do Japão, dos EUA, da Europa e até mesmo de outros países da América Latina.

Também com o modelo Panzar \& Rosse (1987), Araújo, Jorge Neto e Ponce (2006) examinaram os impactos da reestruturação do sistema bancário brasileiro sobre o grau de concentração e o nível de competição da indústria bancária, a partir da intensificação da entrada de bancos estrangeiros no país. O método de dados em painel foi aplicado sobre os dados dos bancos brasileiros de dezembro de 1995 a junho de 2004. Entre as conclusões do trabalho, destacase o fato de que a competição no setor bancário brasileiro aumentou com a entrada de bancos estrangeiros e voltou a cair com sua saída, no âmbito de uma estrutura de concorrência monopolística.

O Método dos Mínimos Quadrado Ordinários - MQO foi o mais utilizado nas estimações do modelo Panzar \& Rosse (1987) sobre dados dos bancos brasileiros. Este foi o caso 
de Nakane e Rocha (2010), Rondon (2011), Cardoso (2011) e Castor (2013). Nakane e Rocha (2010) objetivaram verificar se o aumento da concentração bancária teve impacto no poder de mercado do setor no período de junho/2001 a junho/2010. Os autores concluíram que, a despeito de ter ocorrido aumento da concentração no setor bancário doméstico em razão de fusões e aquisições, haveria uma competição relativamente elevada neste setor no período analisado no trabalho, no âmbito de uma estrutura de concorrência monopolística.

Rondon (2011) enfocou o período 1995-2008, com estimações para dois períodos específicos: 1995-2003 e 2004-2008. No primeiro deles, o indicador de Panzar \& Rosse não apresentou tendência de aumento, situando-se entre 0,60 e 0,69. No segundo período, os resultados sinalizaram haver uma tendência de elevação e, por conseguinte, um aumento da competição na indústria bancária brasileira. Em ambos os períodos, os resultados apontaram que tal indústria operaria em concorrência monopolística.

A análise de Cardoso (2011) baseou-se no setor bancário brasileiro por unidades de negócio (CNPJ) e por conglomerados financeiros no período 1999-2010. Os resultados apontaram haver concorrência monopolística tanto na análise por CNPJ quanto naquela que foi feita por conglomerado financeiro. Já Castor (2013) aplicou o modelo Panzar \& Rosse a informações do setor bancário brasileiro no período de junho de 2002 a dezembro de 2012. Embora também tenha indicado haver concorrência monopolística no mercado bancário doméstico, a estatística $\mathrm{H}$ encontrada manteve-se próxima de 1 , o que sugere que tal mercado operaria de forma próxima à concorrência perfeita.

O estudo de Silveira (2017) fez uso do Método dos Mínimos Quadrado Ordinários MQO com dados empilhados, juntamente com o Feaseble Generalized Least Squares - FGLS. O autor utilizou somente informações dos bancos que realizam operações de crédito a partir da captação de depósitos e aplicou o método de Panzar \& Rosse sobre dois modelos: no primeiro deles, a variável dependente foi a Receita Operacional dos bancos e, no segundo, tal variável foi o quociente entre a Receita Operacional e o Ativo Total dos bancos, ou seja, a ROA. Neste último modelo, a avaliação promoveu outro uso para a estatística $\mathrm{H}$, pois, a partir daí, pôde-se verificar o comportamento competitivo de longo prazo ${ }^{15}$. As conclusões do trabalho se aproximam das de Belaisch (2003), verificando que, apesar de toda a evolução tecnológica e da maior cobertura geográfica dos serviços bancários, o setor bancário brasileiro não possui um nível ótimo de atendimento à sociedade.

Tendo em conta os trabalhos acima, como ver-se-á a seguir, o presente trabalho apresenta resultados baseados em dados mais recentes, do período 2010-2017, trazendo uma atualização do estudo realizado por Cardoso (2011), porém, diferenciando-se fundamentalmente por conta do método utilizado. Neste trabalho, foi utilizada a metodologia desenvolvida por Silveira (2017), envolvendo não apenas os bancos (como fez aquele autor), mas também a análise dos conglomerados financeiros (como fez CARDOSO, 2011) com o objetivo de ampliar e enriquecer a discussão da concorrência do mercado bancário brasileiro.

\section{METODOLOGIA}

\subsection{Os Dados}

Neste trabalho foram selecionados os balancetes mensais dos bancos brasileiros disponíveis no sítio do Banco Central (BC). Estes dados são apresentados pelos seguintes

\footnotetext{
${ }^{15}$ Isto é, a estatística $\mathrm{H}^{\mathrm{ROA}}$ retirada do modelo com o ROA em conjunto com a estatística $\mathrm{H}^{1}$ do modelo original, proporciona a seguinte análise: se $\mathrm{H}^{\mathrm{ROA}}$ igual a $0 \mathrm{e}^{1}$ igual a 1 , o mercado seria competitivo no longo prazo; sendo $\mathrm{H}^{\mathrm{ROA}}$ maior que 0 e $\mathrm{H}^{1}$ menor que 0 , o mercado teria um comportamento de monopólio, oligopólio ou equilíbrio competitivo de longo prazo; por fim, caso ambas $\mathrm{H}^{\mathrm{ROA}} \mathrm{e}^{1}$ forem maiores que 0 , o "desequilíbrio existe, mas o não suficiente para determinar $\mathrm{H}^{1}$ (SILVEIRA, 2017).
} 
relatórios: i) Relatório 4010, com informações por CNPJ, considerando-se cada unidade de negócio como um agente no mercado; ii) Relatório 4020, que apresenta informações por CNPJ, mais resultados das agências no exterior; iii) Relatório 4040, contendo informações por Consolidado Bancário, considerando-se os resultados das subsidiárias e empresas de cada conglomerado bancário que atua no país; e iv) Relatório 4050, que compõe as informações por Consolidado Econômico Financeiro.

Não é incorreto analisar a concentração bancária por meio da análise de CNPJ, ou seja, considerando cada unidade de negócio como uma variável na análise. Entretanto, por essa análise, a concentração do mercado tende a ser subestimada, uma vez que algumas das unidades de negócio pertencem ao mesmo conglomerado financeiro (NAKANE, 2001; CARDOSO, 2011). Diante desta questão, no presente trabalho foram construídas duas bases de dados, sendo a primeira a partir do relatório 4010 e a segunda com os dados constantes do relatório 4040, de modo a captar as diferenças entre os níveis de concentração de mercado para cada tipo de relatório e abranger o mercado sob dois prismas diferentes, tal como fez Cardoso (2011).

Para os cálculos dos índices de concentração e também para a estimação do modelo de Panzar \& Rosse, os critérios para definição e seleção dos dados e também dos agentes que seriam analisados foram os mesmos. Para definição de quais bancos seriam enfocados no estudo, foram considerados, a priori, os que possuíam a conta Operações de Crédito diferente de zero. Como segundo critério de seleção, foram mantidos apenas os bancos que possuíam a conta Depósitos Totais diferente de zero. E, para chegar à seleção final de bancos a serem analisados, foram levados em conta os bancos que possuíam pelo menos uma das seguintes contas diferentes de zero: Depósitos à Vista, Depósitos de Poupança e Depósitos a Prazo. A justificativa para esta seleção é que o objetivo do trabalho é analisar a concentração e a concorrência de mercado dos bancos comerciais, não trazendo para tal análise os bancos de investimento, os de desenvolvimento e as empresas de financiamento de bens duráveis, dado que a captação do montante a se tornar crédito por esses agentes não se dá via depósitos e, portanto, foge do escopo do trabalho.

Abaixo estão listadas as variáveis que foram coletadas a partir dos relatórios 4010 e 4040 do Banco Central para construção da análise empírica (QUADRO 1):

Quadro 1 - Variáveis dos relatórios 4010 e 4040

\begin{tabular}{|l|l|}
\hline 1. Depósitos Totais & 9. Despesas Operacionais \\
2. Depósitos a Prazo & 10. Operações de Crédito \\
3. Depósitos a Vista & 11. Operações de Créditos e Arrendamento Mercantil \\
4. Depósitos de Poupança & 12. Outros Créditos \\
5. Depósitos Interfinanceiros & 13. Outros Valores e Bens \\
6. Desp. de Obrigações por Empréstimos e Repasses & 14. Patrimônio Líquido \\
7. Despesas Administrativas & 15. Receitas Operacionais \\
8. Despesas de Captação & 16. Total Geral do Ativo \\
\hline
\end{tabular}

Fonte: Banco Central (2010...)

Como os relatórios 4010 e 4040 são mensais, os dados foram transformados em trimestrais, utilizando-se o cálculo da média simples dos valores para o período que compreende janeiro/2010 a dezembro/2017. Todos os valores mensais foram deflacionados pelo IPCA, considerando-se o mês de janeiro/2010 como base.

Feito isso, as análises foram realizadas para dois períodos distintos: o primeiro período abrange a gestão de Alexandre Tombini no BC, indo do primeiro trimestre/2011 até o segundo trimestre/2016, totalizando 22 trimestres. E o segundo período é aquele em que o BC seguia a liderança do presidente Ilan Goldfajn que, no caso deste trabalho, vai do terceiro trimestre/2016 até o último trimestre/2017, totalizando 6 trimestres. Dessa forma, o estudo permite avaliar como evoluíram a concentração e a competição na indústria bancária brasileira nesses dois períodos de gestão do BC, sob dois Chefes de Estado diferentes. 


\section{2 Índices de Concentração}

Para aferir a concentração para o mercado bancário brasileiro, foram calculados dois índices para as variáveis Depósitos a Prazo, Total Geral do Ativo e Operações de Crédito, a saber: a Razão de Concentração (C5); e o Herfindahl Hirschman Index (HHI).

Para a Razão de Concentração, foram analisados os cinco principais agentes em cada ano, para cada uma das variáveis. Pela equação (1), abaixo, pode-se ter mais clareza acerca do cálculo desse indicador, sendo C5 o percentual de concentração do grupo composto pelos cinco bancos (ou conglomerados financeiros) com as maiores participações do mercado no setor bancário e bit o percentual de participação de mercado de cada um dos i-ésimos bancos (ou conglomerados financeiros) no período t.

$$
C 5_{t}=\sum_{i=1}^{5} b_{i t}
$$

Já para o cálculo do HHI, é necessária a mensuração da participação de mercado de cada banco, elevando-se a mesma ao quadrado e somando-se todos os dados, tal qual se pode ver pela equação (2) abaixo,

$$
H H I_{t}=\sum_{i=1}^{N} b_{i t}^{2}
$$

em que bi ${ }^{2}$ é o quadrado da participação de cada banco (ou conglomerado financeiro) i no mercado e $\mathrm{N}$ é o número de bancos (ou de conglomerados financeiros) no período t.

O índice $\mathrm{HHI}$ varia de $1 / \mathrm{N}$ até 1 , sendo que $\mathrm{N}$ é o número de agentes no mercado. Segundo o Guia para Análise dos Atos de Concentração Horizontal do CADE, de 2016, um HHI abaixo de $1,0 \%$ (ou de 100 pontos) indica um mercado altamente concorrencial, mas este índice pode chegar a 10.000 pontos, o que indicaria haver um monopólio no mercado. Em números percentuais, pode-se classificar os níveis de concentração de mercado da seguinte maneira: i) mercados não concentrados possuem o HHI menor que $15 \%$; ii) mercados moderadamente concentrados possuem o HHI entre $15 \%$ e $25 \%$; iii) e mercados altamente concentrados contam com HHI acima de $25 \%$.

\subsection{O Modelo Panzar \& Rosse}

Como já dito, para o mercado bancário, a análise apenas por índices de concentração clássicos, como a Razão de Concentração e o Herfindahl Hirschman Index, não é suficiente para se determinar a concorrência no mercado bancário. Para verificar o tipo de concorrência que a indústria bancária brasileira opera, este trabalho fez uso do modelo desenvolvido por Panzar \& Rosse (1987) em seu trabalho Testing for Monopoly Equilibrium.

A equação do modelo Panzar \& Rosse (1987) é composta pelo logaritmo natural da receita total como variável dependente, pelo logaritmo natural dos preços de seus insumos e pelo logaritmo natural as variáveis de controle. Ou seja,

$$
\ln \left(Y_{i t}\right)=\alpha+\Sigma_{\mathrm{t}} \beta_{f} \ln \left(P_{f i t}\right)+\Sigma_{\mathrm{k}} \alpha_{k i t} \ln \left(\mathrm{C}_{k i t}\right)+\varepsilon_{i t}
$$


onde $Y_{i t}$ é a receita total no período t; $P_{f i t}$ é o preço dos insumos do banco no período t; e $\mathrm{C}_{k i t}$ representa as variáveis de controle do modelo no período $t$.

Por sua vez, estatística H, resultante do modelo Panzar \& Rosse, é a soma dos coeficientes das variáveis de preço dos insumos, ou seja, a soma das elasticidades da receita dos bancos em relação aos preços de seus insumos. A equação (4) apresenta a estatística $\mathrm{H}$ :

$$
\mathrm{H}=\sum_{f} \beta_{f}
$$

A estimação da estatística $\mathrm{H}$ busca classificar o mercado pelo tipo de concorrência, sendo que, se $\mathrm{H} \leq 0$, o mercado é monopolizado; se $0<\mathrm{H}<1$, o mercado opera em concorrência monopolística; e, por fim, se $\mathrm{H}=1$, o mercado operaria em concorrência perfeita.

Seguindo a metodologia utilizada por Silveira (2017), o presente trabalho trata como preços dos insumos as seguintes despesas provenientes dos relatórios do BC: i) Despesas de juros; ii) Despesas administrativas; e iii) Despesas operacionais. As variáveis dependentes e as variáveis de controle utilizadas nos modelos estimados estão apresentadas no Quadro 2.

\begin{tabular}{|c|l|}
\multicolumn{4}{|c|}{ Quadro 2: Variáveis Utilizadas nos Modelos Estimados } \\
\hline Variável & \multicolumn{1}{c|}{ Descrição } \\
\hline Y & Logaritmo natural das receitas operacionais totais \\
P1 & Logaritmo natural da razão entre as despesas com juros e o total depósitos \\
P2 & Logaritmo natural da razão entre as despesas operacionais e o ativo total \\
P3 & Logaritmo natural da razão entre as despesas administrativas e o ativo total \\
C1 & Logaritmo natural da razão entre as operações de crédito e arrendamento \\
& mercantil e o ativo total \\
C2 & Logaritmo natural da razão entre os outros créditos e o ativo total \\
C3 & Logaritmo natural da razão entre os depósitos de clientes e os depósitos \\
& de clientes mais os fundos de curto prazo \\
C4 & Logaritmo natural da razão entre o patrimônio líquido e o ativo total \\
\hline
\end{tabular}

Fonte: Elaboração própria.

Espera-se os coeficientes das variáveis que representam as despesas com juros e captação (P1) e as despesas operacionais (P2) sejam positivos, sinalizando que o aumento dos gastos com funcionários ou com captação gera um incremento na receita do banco; e, ao contrário, que os sinais das variáveis que representam os custos administrativos (P3) sejam negativos, evidenciando que uma elevação desses custos acarreta num decréscimo da receita do banco, dando sentido de ineficiência.

\subsection{Método de Estimação}

O método mais utilizado nos trabalhos empíricos que estudam o tema em epígrafe é o Método dos Mínimos Quadrados Ordinários - MQO. Entretanto, segundo Silveira (2017), ao estimar o modelo pelo MQO, utilizando as receitas operacionais dos bancos, tende-se a gerar o problema de heterocedasticidade, dado que as diferenças entre as receitas operacionais podem ser enormes de um banco para outro, o que provocaria erro na estimação da estatística $\mathrm{H}$.

Para correção desse problema, pode-se utilizar o método Feaseble Generalized Least Squares - FGLS, ou seja, uma alternativa ao MQO que possui uma estimação mais robusta que o primeiro método. Em outras palavras, "FGLS is an attractive alternative to OLS when there is evidence of heteroskedasticity that inflates the standard errors of the OLS estimates" (WOOLDRIDGE, 2012 p. 287).

Segundo Wooldridge (2012), para corrigir o problema da heterocedasticidade, o método FGLS estima uma regressão pelo método MQO para obter os resíduos e os utiliza para ponderar as variáveis originais. Após estes procedimentos, o próprio método estima outra 
regressão pelo método MQO sobre as variáveis modificadas, obtendo um novo modelo, cujos coeficientes são melhores estimadores do que o modelo original, uma vez que o modelo final possui erros com variância constante, ou seja, homoscedástica.

\section{RESULTADOS E DISCUSSÃO}

Primeiramente, serão apresentados nesta seção os resultados das análises dos índices de concentração para as variáveis de Depósitos a Prazo, Total Geral do Ativo e Operações de Crédito, separando-as por CNPJ e por conglomerados financeiros.

\subsection{Resultados dos Índices Clássicos de Concentração C5 e HHI}

\subsubsection{Relatório 4010: Análise por CNPJ}

Ao analisar o Relatório 4010, que considera os bancos como cada unidade de negócio, verifica-se a alta participação dos cinco maiores bancos no mercado de crédito em todos os anos do estudo, com a soma das participações sempre acima de 70\% (TABELA 1). Considerando todo o período, percebe-se que a participação de mercado desse grupo atinge uma média de $76,8 \%$. Destaca-se o Banco do Brasil, cuja participação média no período foi de $25,1 \%$ no mercado de operações de crédito brasileiro, e a evolução da participação da Caixa Econômica Federal, que saiu de 14,3\%, em 2010, e atingiu o maior nível em 2017, despontando-se com o maior market share do grupo, com $31,5 \%$.

Tabela 1: C5 para Operações de Crédito: Análise por CNPJ

\begin{tabular}{l|c|c|c|c|c|c|c|c|c}
\hline \multicolumn{1}{c}{ ANO } & $\mathbf{2 0 1 0}$ & $\mathbf{2 0 1 1}$ & $\mathbf{2 0 1 2}$ & $\mathbf{2 0 1 3}$ & $\mathbf{2 0 1 4}$ & $\mathbf{2 0 1 5}$ & $\mathbf{2 0 1 6}$ & $\mathbf{2 0 1 7}$ & $\begin{array}{c}\text { Média } \\
\text { Período }\end{array}$ \\
\hline BANCO DO BRASIL & $25,2 \%$ & $24,6 \%$ & $24,6 \%$ & $25,4 \%$ & $25,6 \%$ & $25,5 \%$ & $25,6 \%$ & $24,4 \%$ & $25,1 \%$ \\
\hline CAIXA ECONOMICA FEDERAL & $14,3 \%$ & $16,7 \%$ & $20,0 \%$ & $23,4 \%$ & $25,9 \%$ & $28,1 \%$ & $29,9 \%$ & $31,5 \%$ & $23,7 \%$ \\
\hline BCO BRADESCO & $12,3 \%$ & $12,6 \%$ & $11,7 \%$ & $10,8 \%$ & $10,2 \%$ & $10,0 \%$ & $10,0 \%$ & $10,8 \%$ & $11,1 \%$ \\
\hline ITAÚ UNIBANCO & $9,7 \%$ & $10,1 \%$ & $9,1 \%$ & $7,7 \%$ & $10,1 \%$ & $9,8 \%$ & $9,2 \%$ & $9,3 \%$ & $9,4 \%$ \\
\hline BCO SANTANDER & $9,5 \%$ & $9,2 \%$ & $8,4 \%$ & $7,2 \%$ & $6,4 \%$ & $6,3 \%$ & $6,3 \%$ & $6,5 \%$ & $7,5 \%$ \\
\hline $\boldsymbol{C 5}$ & $\mathbf{7 1 , 1 \%}$ & $\mathbf{7 3 , 3 \%}$ & $\mathbf{7 3 , 7 \%}$ & $\mathbf{7 4 , 5 \%}$ & $\mathbf{7 8 , 3 \%}$ & $\mathbf{7 9 , 8 \%}$ & $\mathbf{8 0 , 9 \%}$ & $\mathbf{8 2 , 5 \%}$ & $\mathbf{7 6 , 8 \%}$ \\
\hline
\end{tabular}

Fonte: Elaboração própria a partir do Relatório 4010 do Banco Central.

Já na Tabela 2, a variável Total Geral do Ativo possuía, nos dois primeiros anos da análise, o Banco Itaú BBA como integrante do grupo dos cinco bancos com maior participação de mercado e, nos anos seguintes, a Caixa Econômica entrou para o grupo, com uma participação maior que a daquele banco e com um forte crescimento ano a ano no período analisado. Observase também uma tendência de crescimento do market share dos bancos Bradesco, Banco do Brasil, Itaú e Caixa Econômica, em detrimento, inicialmente do Itaú BBA, que saiu do grupo dos 5 maiores após 2011, e depois do Banco Santander.

Tabela 2: C5 para Total Geral do Ativo: Análise por CNPJ

\begin{tabular}{l|c|c|c|c|c|c|c|c|c}
\hline \multicolumn{1}{c}{ ANO } & $\mathbf{2 0 1 0}$ & $\mathbf{2 0 1 1}$ & $\mathbf{2 0 1 2}$ & $\mathbf{2 0 1 3}$ & $\mathbf{2 0 1 4}$ & $\mathbf{2 0 1 5}$ & $\mathbf{2 0 1 6}$ & $\mathbf{2 0 1 7}$ & $\begin{array}{c}\text { Média } \\
\text { Período }\end{array}$ \\
\hline BCO SANTANDER & $22,5 \%$ & $17,6 \%$ & $16,2 \%$ & $6,8 \%$ & $9,4 \%$ & $10,3 \%$ & $8,7 \%$ & $5,8 \%$ & $12,2 \%$ \\
\hline BCO BRADESCO & $12,2 \%$ & $13,8 \%$ & $15,0 \%$ & $15,9 \%$ & $14,5 \%$ & $13,6 \%$ & $14,0 \%$ & $15,3 \%$ & $14,3 \%$ \\
\hline BANCO DO BRASIL & $11,5 \%$ & $13,5 \%$ & $15,9 \%$ & $17,8 \%$ & $19,7 \%$ & $18,2 \%$ & $18,3 \%$ & $16,7 \%$ & $16,5 \%$ \\
\hline BCO ITAU BBA & $10,8 \%$ & $5,9 \%$ & - & - & - & - & - & - & $8,3 \%$ \\
\hline
\end{tabular}




\begin{tabular}{l|c|c|c|c|c|c|c|c|c} 
ITAU UNIBANCO & $10,1 \%$ & $11,1 \%$ & $12,0 \%$ & $13,7 \%$ & $17,5 \%$ & $16,9 \%$ & $18,4 \%$ & $18,1 \%$ & $14,7 \%$ \\
\hline CAIXA ECONOMICA & & & & & & & & $16,8 \%$ & $13,8 \%$ \\
FEDERAL & - & - & $9,6 \%$ & $12,3 \%$ & $13,6 \%$ & $14,5 \%$ & $15,6 \%$ & $16,8 \%$ \\
\hline $\boldsymbol{C 5}$ & $\mathbf{6 7 , 1 \%}$ & $\mathbf{6 1 , 9 \%}$ & $\mathbf{6 8 , 8} \%$ & $\mathbf{6 6 , 6 \%}$ & $\mathbf{7 4 , 8 \%}$ & $\mathbf{7 3 , 6 \%}$ & $\mathbf{7 5 , 0 \%}$ & $\mathbf{7 2 , 7 \%}$ & $\mathbf{7 0 , 0 \%}$ \\
\hline
\end{tabular}

Fonte: Elaboração própria a partir do Relatório 4010 do Banco Central.

Para a variável Depósitos a Prazo, no primeiro ano, o $\mathrm{HSBC}^{16}$ apresenta 8,9\%, entrentanto, sua participação não perdurou nos anos seguintes, com a Caixa Econômica assumindo novamente uma forte posição no grupo, com um crescimento vertiginoso do seu market share na categoria de captação de recursos. Destaca-se novamente a tendência crescente da concentração no mercado bancário, com o C5 saindo de 68,9\%, em 2010, para 77,9\% em 2017 (TABELA 3).

Tabela 3: C5 para Depósitos a Prazo: Análise por CNPJ

\begin{tabular}{l|c|c|c|c|c|c|c|c|c}
\hline \multicolumn{1}{c|}{ ANO } & $\mathbf{2 0 1 0}$ & $\mathbf{2 0 1 1}$ & $\mathbf{2 0 1 2}$ & $\mathbf{2 0 1 3}$ & $\mathbf{2 0 1 4}$ & $\mathbf{2 0 1 5}$ & $\mathbf{2 0 1 6}$ & $\mathbf{2 0 1 7}$ & $\begin{array}{c}\text { Média do } \\
\text { Período }\end{array}$ \\
\hline BANCO DO BRASIL & $24,4 \%$ & $26,4 \%$ & $30,3 \%$ & $29,5 \%$ & $27,7 \%$ & $24,8 \%$ & $22,8 \%$ & $19,0 \%$ & $25,6 \%$ \\
\hline BCO BRADESCO & $13,5 \%$ & $13,6 \%$ & $11,5 \%$ & $10,2 \%$ & $9,1 \%$ & $7,5 \%$ & $8,2 \%$ & $12,2 \%$ & $10,7 \%$ \\
\hline ITAU UNIBANCO & $12,9 \%$ & $11,1 \%$ & $9,1 \%$ & $8,3 \%$ & $8,7 \%$ & $8,1 \%$ & $7,9 \%$ & $11,0 \%$ & $9,6 \%$ \\
\hline BCO SANTANDER & $9,2 \%$ & $9,1 \%$ & $9,7 \%$ & $10,5 \%$ & $10,7 \%$ & $11,0 \%$ & $10,4 \%$ & $12,8 \%$ & $10,4 \%$ \\
\hline HSBC BANK BRASIL & $8,9 \%$ & & & & & & & & $8,9 \%$ \\
\hline CAIXA ECONOMICA FEDERAL & & $6,4 \%$ & $10,4 \%$ & $14,8 \%$ & $18,0 \%$ & $22,4 \%$ & $25,2 \%$ & $23,0 \%$ & $17,2 \%$ \\
\hline
\end{tabular}

Fonte: Elaboração própria a partir do Relatório 4010 do Banco Central.

Vale ressaltar a presença dos bancos com controle público (Banco do Brasil e Caixa Econômica Federal) no mercado: para o mercado de crédito, a participação dos dois bancos foi de $56,0 \%$ no ano de 2017 , com uma média de $48,9 \%$ para o período analisado. Para o mercado de captação de recursos via depósitos a prazo, a soma das participações dos bancos de controle estatal chegou a $41,9 \%$ no último ano e, na média do período ficou em 40,6\%, observando-se uma manutenção do poder de mercado dos bancos públicos com tendência crescente no período analisado.

No caso do HHI (Herfindahl Hirschman Index, em linhas gerais, as três variáveis analisadas indicaram ter ocorrido aumento concentração de mercado entre 2010 e 2017, embora as variáveis Total Geral do Ativo e Depósitos a Prazo tenham verificado quedas pontuais em alguns dos anos do período analisado ${ }^{17}$.

Tabela 4: HHI para as três categorias escolhidas: Análise por CNPJ

\begin{tabular}{c|c|c|c}
\hline Conta / ano & $\begin{array}{c}\text { OPERACÕES } \\
\text { DE CRÉDITO }\end{array}$ & $\begin{array}{c}\text { TOTAL GERAL } \\
\text { DO ATIVO }\end{array}$ & $\begin{array}{c}\text { DEPÓSITOS } \\
\text { A PRAZO }\end{array}$ \\
\hline 2010 & $12,18 \%$ & $11,37 \%$ & $11,89 \%$ \\
\hline 2011 & $12,70 \%$ & $10,22 \%$ & $12,42 \%$ \\
\hline 2012 & $13,27 \%$ & $10,85 \%$ & $13,92 \%$ \\
\hline 2013 & $14,53 \%$ & $10,90 \%$ & $14,14 \%$ \\
\hline 2014 & $15,98 \%$ & $12,24 \%$ & $14,12 \%$ \\
\hline 2015 & $16,94 \%$ & $11,68 \%$ & $14,08 \%$ \\
\hline
\end{tabular}

\footnotetext{
16 Todas as operações do banco HSBC no Brasil foram adquiridas pelo Bradesco em agosto de 2015 por US\$ 5,2 bilhões (BRADESCO, ..., 2016).

${ }^{17}$ O HHI do Total Geral do Ativo caiu em 2015 na comparação com 2014 e o dos Depósitos a Prazo caiu em 2014 e em 2015 e depois em 2017.
} 


\begin{tabular}{l|l|l|l}
2016 & $17,85 \%$ & $12,27 \%$ & $14,41 \%$ \\
\hline 2017 & $18,44 \%$ & $12,48 \%$ & $13,58 \%$ \\
\hline
\end{tabular}

Fonte: Elaboração própria a partir do Relatório 4010 do Banco Central.

Tendo como referência o Guia para Análise dos Atos de Concentração Horizontal do CADE, para essas duas últimas variáveis, o HHI apurado indica não haver grande concentração na indústria bancária brasileira. Por outro lado, para as Operações de Crédito, o HHI superou o segundo nível de classificação (com HHI superior a 15\%) em 2015, atingindo 18,44\% no ano de 2017 (TABELA 4). Vejamos na próxima seção como se comportam estes índices de concentração na análise por conglomerado.

\subsection{2 Índices de Concentração - Relatório 4040: Análise por Conglomerado financeiro}

Nesta seção, foram calculados os índices de concentração C5 e o HHI para o Relatório 4040, que permite que as análises sejam feitas por conglomerado financeiro. Os resultados foram consideravelmente diferentes para os dois tipos de relatórios, com um nível de concentração bem maior para as análises para o segundo do que para o primeiro. Como sinalizado por Cardoso (2011), quando se analisa a participação de mercado por meio dos dados dos conglomerados financeiros, além da amostra ser menor, considera-se a participação conjunta daqueles agentes que pertencem a um mesmo grupo, de modo a se ter a participação do grupo como um todo. Para efeitos de comparação, analisando o mercado de crédito, verifica-se que a média do C5 dos conglomerados financeiros para o período foi de $82,8 \%$ (TABELA 5) contra 76,8\% na análise por CNPJ (TABELA 2).

Tabela 5: C5 para Operações de Crédito: Conglomerado Financeiro

\begin{tabular}{l|c|c|c|c|c|c|c|c|c}
\hline \multicolumn{1}{c|}{ ANO } & $\mathbf{2 0 1 0}$ & $\mathbf{2 0 1 1}$ & $\mathbf{2 0 1 2}$ & $\mathbf{2 0 1 3}$ & $\mathbf{2 0 1 4}$ & $\mathbf{2 0 1 5}$ & $\mathbf{2 0 1 6}$ & $\mathbf{2 0 1 7}$ & $\begin{array}{c}\text { Média do } \\
\text { período }\end{array}$ \\
\hline BB & $28,1 \%$ & $26,9 \%$ & $28,5 \%$ & $31,4 \%$ & $33,1 \%$ & $33,0 \%$ & $32,7 \%$ & $32,1 \%$ & $30,7 \%$ \\
\hline ITAU & $19,3 \%$ & $20,4 \%$ & $20,3 \%$ & $19,6 \%$ & $19,9 \%$ & $20,5 \%$ & $21,9 \%$ & $22,9 \%$ & $20,6 \%$ \\
\hline BRADESCO & $16,9 \%$ & $17,2 \%$ & $16,9 \%$ & $16,6 \%$ & $16,5 \%$ & $16,2 \%$ & $16,7 \%$ & $17,3 \%$ & $16,8 \%$ \\
\hline SANTANDER & $12,7 \%$ & $12,5 \%$ & $12,3 \%$ & $11,4 \%$ & $10,8 \%$ & $11,1 \%$ & $10,7 \%$ & $11,7 \%$ & $11,7 \%$ \\
\hline VOTORANTIM & $4,6 \%$ & $4,6 \%$ & $3,8 \%$ & $2,4 \%$ & - & - & $1,1 \%$ & - & $3,3 \%$ \\
\hline HSBC & - & - & - & - & $3,0 \%$ & $2,2 \%$ & - & - & $2,6 \%$ \\
\hline SAFRA & - & - & - & - & & - & - & $2,5 \%$ & $2,5 \%$ \\
\hline C5 & $\mathbf{8 1 , 6 \%}$ & $\mathbf{8 1 , 5 \%}$ & $\mathbf{8 1 , 8 \%}$ & $\mathbf{8 1 , 4 \%}$ & $\mathbf{8 3 , 3 \%}$ & $\mathbf{8 3 , 0 \%}$ & $\mathbf{8 3 , 2 \%}$ & $\mathbf{8 6 , 6 \%}$ & $\mathbf{8 2 , 8 \%}$ \\
\hline
\end{tabular}

Fonte: Elaboração própria a partir do Relatório 4040 do Banco Central.

Em relação ao Total Geral do Ativo, novamente é observado um índice de concentração maior para a análise do conglomerado financeiro em relação à análise por CNPJ. A participação dos cinco maiores conglomerados financeiros no Total Geral do Ativo do setor sempre ficou próxima dos 80,0\% no período analisado (TABELA 6). Destaca-se a participação do conglomerado do Itaú, que chegou a bater os 32,5\% no último ano, sendo um número alto em relação aos demais conglomerados.

Tabela 6: C5 para Total Geral do Ativo: Conglomerado Financeiro

\begin{tabular}{l|c|c|c|c|c|c|c|c|c}
\hline \multicolumn{1}{c|}{ ANO } & $\mathbf{2 0 1 0}$ & $\mathbf{2 0 1 1}$ & $\mathbf{2 0 1 2}$ & $\mathbf{2 0 1 3}$ & $\mathbf{2 0 1 4}$ & $\mathbf{2 0 1 5}$ & $\mathbf{2 0 1 6}$ & $\mathbf{2 0 1 7}$ & $\begin{array}{c}\text { Média do } \\
\text { período }\end{array}$ \\
\hline ITAU & $26,2 \%$ & $25,6 \%$ & $29,6 \%$ & $31,4 \%$ & $27,3 \%$ & $27,5 \%$ & $31,8 \%$ & $32,5 \%$ & $29,0 \%$ \\
\hline SANTANDER & $21,4 \%$ & $16,5 \%$ & $14,6 \%$ & $8,5 \%$ & $9,3 \%$ & $10,4 \%$ & $8,9 \%$ & $8,1 \%$ & $12,2 \%$ \\
\hline
\end{tabular}




\begin{tabular}{l|c|c|c|c|c|c|c|c|c} 
BRADESCO & $13,3 \%$ & $15,3 \%$ & $16,3 \%$ & $17,7 \%$ & $16,6 \%$ & $14,6 \%$ & $15,5 \%$ & $17,1 \%$ & $15,8 \%$ \\
\hline BB & $13,1 \%$ & $15,3 \%$ & $16,9 \%$ & $18,7 \%$ & $21,1 \%$ & $19,0 \%$ & $18,8 \%$ & $17,6 \%$ & $17,6 \%$ \\
\hline VOTORANTIM & $3,1 \%$ & $5,3 \%$ & - & - & - & - & - & - & $4,2 \%$ \\
\hline BTG PACTUAL & - & & $4,5 \%$ & $4,8 \%$ & $5,1 \%$ & $7,4 \%$ & $5,5 \%$ & $4,5 \%$ & $5,3 \%$ \\
\hline $\mathbf{C 5}$ & $\mathbf{7 7 , 2 \%}$ & $\mathbf{7 8 , 0 \%}$ & $\mathbf{8 2 , 0} \%$ & $\mathbf{8 1 , 2 \%}$ & $\mathbf{7 9 , 3 \%}$ & $\mathbf{7 8 , 9 \%}$ & $\mathbf{8 0 , 4 \%}$ & $\mathbf{7 9 , 7 \%}$ & $\mathbf{7 9 , 6 \%}$ \\
\hline
\end{tabular}

Fonte: Elaboração própria a partir do Relatório 4040 do Banco Central.

Para o mercado de captação, houve uma concentração menor em relação à análise por CNPJ, porém, depois de superar 50,0\% a partir de 2014, o C5 não voltou a ficar abaixo desse patamar, com o pico de 61,9\% em 2015 (TABELA 7).

Tabela 7: C5 para Depósitos a Prazo: Conglomerado Financeiro

\begin{tabular}{l|c|c|c|c|c|c|c|c|c}
\hline \multicolumn{1}{c|}{ ANO } & $\mathbf{2 0 1 0}$ & $\mathbf{2 0 1 1}$ & $\mathbf{2 0 1 2}$ & $\mathbf{2 0 1 3}$ & $\mathbf{2 0 1 4}$ & $\mathbf{2 0 1 5}$ & $\mathbf{2 0 1 6}$ & $\mathbf{2 0 1 7}$ & $\begin{array}{c}\text { Média do } \\
\text { período }\end{array}$ \\
\hline BB & $13,0 \%$ & $12,3 \%$ & $13,8 \%$ & $18,5 \%$ & $21,7 \%$ & $23,1 \%$ & $22,2 \%$ & $19,2 \%$ & $18,0 \%$ \\
\hline ITAU & $8,3 \%$ & $8,2 \%$ & $9,5 \%$ & $13,4 \%$ & $16,5 \%$ & $17,9 \%$ & $15,8 \%$ & $14,0 \%$ & $12,9 \%$ \\
\hline BRADESCO & $7,7 \%$ & $7,4 \%$ & $8,1 \%$ & $10,6 \%$ & $12,6 \%$ & $14,2 \%$ & $13,5 \%$ & $12,2 \%$ & $10,8 \%$ \\
\hline SANTANDER & $4,3 \%$ & $3,9 \%$ & $3,2 \%$ & $4,3 \%$ & $5,3 \%$ & $5,7 \%$ & $5,2 \%$ & $4,7 \%$ & $4,6 \%$ \\
\hline HSBC & $0,5 \%$ & $0,5 \%$ & $0,7 \%$ & $0,9 \%$ & $1,0 \%$ & $1,0 \%$ & $0,4 \%$ & - & $0,7 \%$ \\
\hline BANRISUL & - & - & - & - & - & - & - & $1,0 \%$ & $1,0 \%$ \\
\hline C5 & $\mathbf{3 3 , 9 \%}$ & $\mathbf{3 2 , 3 \%}$ & $\mathbf{3 5 , 2 \%}$ & $\mathbf{4 7 , 7 \%}$ & $\mathbf{5 7 , 2 \%}$ & $\mathbf{6 1 , 9 \%}$ & $\mathbf{5 7 , 1 \%}$ & $\mathbf{5 1 , 1 \%}$ & $\mathbf{4 7 , 1 \%}$ \\
\hline
\end{tabular}

Fonte: Elaboração própria a partir do Relatório 4040 do Banco Central.

Em relação ao HHI, a Tabela 8 o apresenta para os conglomerados financeiros como um todo para as Operações e Crédito, para o Ativo Total Geral e para os Depósitos a Prazo. A comparação dos resultados dessa Tabela com os da Tabela 4 deixa clara a maior concentração de mercado na análise do mercado para os conglomerados financeiros em relação àquela feita por CNPJ. Na análise por conglomerado, o mercado já está em um nível de concentração moderado (pela classificação do CADE) para todos os anos e todas as categorias, excluindo-se apenas a variável Total Geral do Ativo no ano de 2011 (TABELA 9). Já na análise por CNPJ, apenas para as Operações de Crédito a concentração de mercado chegou ao segundo nível e somente a partir do ano de 2014 (TABELA 4).

Tabela 8: HHI para as três categorias escolhidas: Conglomerado financeiro

\begin{tabular}{c|c|c|c}
\hline $\begin{array}{c}\text { Conta / } \\
\text { ano }\end{array}$ & $\begin{array}{c}\text { OPERACÕES DE } \\
\text { CRÉDITO }\end{array}$ & $\begin{array}{c}\text { TOTAL GERAL } \\
\text { DO ATIVO }\end{array}$ & $\begin{array}{c}\text { DEPÓSITOS A } \\
\text { PRAZO }\end{array}$ \\
\hline 2010 & $16,56 \%$ & $15,93 \%$ & $15,05 \%$ \\
\hline 2011 & $16,39 \%$ & $14,79 \%$ & $15,91 \%$ \\
\hline 2012 & $17,05 \%$ & $16,92 \%$ & $17,79 \%$ \\
\hline 2013 & $18,08 \%$ & $17,87 \%$ & $18,43 \%$ \\
\hline 2014 & $19,09 \%$ & $16,14 \%$ & $17,74 \%$ \\
\hline 2015 & $19,25 \%$ & $15,41 \%$ & $16,60 \%$ \\
\hline 2016 & $19,72 \%$ & $17,47 \%$ & $16,59 \%$ \\
\hline 2017 & $20,13 \%$ & $18,07 \%$ & $16,35 \%$ \\
\hline
\end{tabular}

Fonte: Elaboração própria a partir do Relatório 4040 do Banco Central. 
Esses resultados evidenciam a importância de realizar as análises da concentração também para os conglomerados financeiros e não apenas para os bancos considerados individualmente. Na próxima seção, será realizada a análise da competição nesse mercado por meio da estimação do modelo Panzar \& Rose.

\subsection{Análise da concorrência no mercado bancário pelo Modelo Panzar \& Rosse}

Os resultados do modelo Panzar \& Rosse apresentados nesta seção vão na mesma linha indicada pelos índices C5 e HHI, expostos anteriormente e, analisam o mercado bancário brasileiro tanto para os dados de unidade de negócio (CNPJ), como para os dados de conglomerado financeiro. Com a utilização do modelo FGLS para todo o período, foram obtidos resultados com alta significância estatística e os sinais dos coeficientes das variáveis que determinam a estatística $\mathrm{H}$ tais quais eram esperados (TABELA 9).

Tabela 9: Resultados das estimações do modelo Panzar \& Rosse para o período total (2010-2017)

\begin{tabular}{|c|c|c|}
\hline $\begin{array}{c}\text { Variável } \\
\text { independente }\end{array}$ & Bancos 2010-2017 & Conglomerados 2010-2017 \\
\hline$P 1$ & $\begin{array}{c}0,0797 * * * \\
(0,0229)\end{array}$ & $\begin{array}{l}0,0695 * \\
(0,0409)\end{array}$ \\
\hline$P 2$ & $\begin{array}{c}0,9986 * * * \\
(0,0355)\end{array}$ & $\begin{array}{c}1,1070 * * * \\
(0,0551)\end{array}$ \\
\hline$P 3$ & $\begin{array}{c}-0,5471 * * * \\
(0,0286)\end{array}$ & $\begin{array}{c}-0,7535 * * * \\
(0,0473)\end{array}$ \\
\hline$C l$ & $\begin{array}{c}0,0490 * * \\
(0,0206)\end{array}$ & $\begin{array}{c}0,5034 * * * \\
(0,0417)\end{array}$ \\
\hline$C 2$ & $\begin{array}{c}0,2088 * * * \\
(0,0243)\end{array}$ & $\begin{array}{c}0,2247 * * * \\
(0,0481)\end{array}$ \\
\hline$C 3$ & $\begin{array}{c}-0,1292 * * * \\
(0,0141)\end{array}$ & $\begin{array}{c}0,2936 * * * \\
(0,0618)\end{array}$ \\
\hline$C 4$ & $\begin{array}{c}-1,4727 * * * \\
(0,0303)\end{array}$ & $\begin{array}{c}-1,5409 * * * \\
(0,0656)\end{array}$ \\
\hline \multirow[t]{4}{*}{ Const. } & $\begin{array}{c}15,7424 * * * \\
(0,1717)\end{array}$ & $\begin{array}{c}16,4630 * * * \\
(0,2830)\end{array}$ \\
\hline & N. Obs.: 3.969 & N. Obs.: 1.853 \\
\hline & Wald & Wald Chi: 1514,78 \\
\hline & Prob. Chi: 0,000 & 0,000 \\
\hline
\end{tabular}

Fonte: Elaboração própria.

A Tabela 9 apresenta esses resultados para os bancos como unidades de negócio (ou seja, relatório 4010 do BC) e para os conglomerados financeiros (relatório 4040 do BC). Observase que os dois modelos trouxeram coeficientes com níveis de significância aceitáveis, com apenas uma variável de controle com o p-valor acima de $1 \%$ no caso do modelo com informações por CNPJ. Para o modelo com dados de conglomerados, a variável de despesas de juros sobre total de depósitos, ou seja, custo de captação, obteve uma significância menor, porém dentro do limite de $10 \%$ para o p-valor.

Somando os coeficientes $\beta$ estimados para as variáveis P1, P2 e P3, obteve-se as estatísticas $\mathrm{H}$ para cada uma das análises. Os resultados encontrados para as estatísticas $\mathrm{H}$ por CNPJ e por conglomerados financeiros foram, respectivamente 0,5313 e 0,4230 . Na Tabela 10 constam os valores da estatística $\mathrm{H}$ apurados nos trabalhos que utilizaram o modelo Panzar \& Rosse para analisar a competição na indústria bancária brasileira. Observando-a, percebe-se que os resultados encontrados aqui ficaram entre os menores (de SILVEIRA, 2017) e os maiores valores (de NAKANE; ROCHA, 2010) observados nos outros trabalhos e sugerem que o mercado em epígrafe opera em concorrência monopolística. 
Tabela 10: Resultados da estatística $\mathrm{H}$ dos trabalhos que utilizaram o modelo Panzar \& Rosse para analisar a concorrência da indústria bancária brasileira

\begin{tabular}{lc}
\hline Autor(es) & Estatística H \\
\hline Araújo; Jorge Neto e Ponce (2006) & 0,736 \\
Nakane; Rocha (2010) & 0,797 \\
Rondon (2011) & 0,665 \\
Cardoso (2011) & 0,739 \\
Castor (2013) & 0,350 (para bancos por CNPJ); 0298 (para conglomerados) \\
Silveira (2017) & $0,191$ (método $M Q O)$ e 0,124 (método $F G L S$ ) \\
\hline
\end{tabular}

Fonte: Elaboração própria.

A Tabela 11 contém os resultados das estimações do modelo Panzar \& Rosse para os dois períodos de gestão do BC analisados neste trabalho, separando-os por CNPJ e por conglomerados financeiros. Com base nesses resultados, foram encontradas as estatísticas $\mathrm{H}$ e estas inseridas na Tabela 12. A comparação dessas estatísticas indica que a gestão Goldfajn contou com maior concorrência no setor bancário doméstico em relação à gestão Tombini, tanto no que tange tanto aos conglomerados financeiros $(\mathrm{H}=0,4768$ contra $\mathrm{H}=0,3600$, respectivamente para cada gestão) quanto em relação aos bancos por CNPJ $(\mathrm{H}=0,7983$ contra $\mathrm{H}=0,5037)$.

Tabela 11: Resultados estimações do modelo Panzar \& Rosse por período de liderança no Banco

\begin{tabular}{|c|c|c|c|c|}
\hline $\begin{array}{c}\text { Variável } \\
\text { independente }\end{array}$ & $\begin{array}{c}\text { Bancos-Era } \\
\text { Tombini }\end{array}$ & $\begin{array}{c}\text { Bancos-Era } \\
\text { Goldfajn }\end{array}$ & $\begin{array}{c}\text { Conglomerados - } \\
\text { Era Tombini }\end{array}$ & $\begin{array}{c}\text { Conglomerados - Era } \\
\text { Goldfajn }\end{array}$ \\
\hline \multirow[t]{2}{*}{$P 1$} & $0,0541 *$ & $0,1806 * * *$ & $0,1096 * *$ & 0,0096 \\
\hline & $(0,0290)$ & $(0,0440)$ & $(0,0492)$ & $(0,0913)$ \\
\hline \multirow[t]{2}{*}{$P 2$} & $1,0369 * * *$ & $1,0210 * * *$ & $0,9863 * * *$ & $1,2597 * * *$ \\
\hline & $(0,0433)$ & $(0,0750)$ & $(0,0646)$ & $(0,1306)$ \\
\hline \multirow[t]{2}{*}{$P 3$} & $-0,5873 * * *$ & $-0,4032 * * *$ & $-0,7359 * * *$ & $-0,7925 * * *$ \\
\hline & $(0,0352)$ & $(0,0610)$ & $(0,0568)$ & $(0,1026)$ \\
\hline \multirow[t]{2}{*}{$C 1$} & 0,0374 & $0,1819 * * *$ & $0,5152 * * *$ & $0,5299 * * *$ \\
\hline & $(0,0246)$ & $(0,0478)$ & $(0,0500)$ & $(0,0933)$ \\
\hline \multirow[t]{2}{*}{$C 2$} & $0,1892 * * *$ & $0,1159 * *$ & $0,2956 * * *$ & $-0,0384$ \\
\hline & $(0,0301)$ & $(0,0514)$ & $(0,0545)$ & $(0,1133)$ \\
\hline \multirow[t]{2}{*}{$C 3$} & $-0,1440 * * *$ & $-0,1413 * * *$ & $0,2822 * * *$ & 0,1817 \\
\hline & $(0,0177)$ & $(0,0251)$ & $(0,0691)$ & $(0,1548)$ \\
\hline \multirow[t]{2}{*}{ C4 } & $-1,4909 * * *$ & $-1,6452 * * *$ & $-1,6569 * * *$ & $-1,4746 * * *$ \\
\hline & $(0,0374)$ & $(0,0657)$ & $(0,0788)$ & $(0,1496)$ \\
\hline \multirow[t]{3}{*}{ Const. } & $15,4188 * * *$ & $16,3794 * * *$ & $16,0641 * * *$ & $15,9557 * * *$ \\
\hline & $(0,2173)$ & $(0,3551)$ & $(0,3489)$ & $(0,5915)$ \\
\hline & N. Obs.: 2.731 & N. Obs.: 742 & N.Obs.: 1.276 & N. Obs.: 347 \\
\hline Wald Chi: & $4363,04 \quad 1366,73$ & 1181,77 & 278,85 & \\
\hline Prob. Chi: & 0,000 & 0,000 & 0,000 & \\
\hline
\end{tabular}

Fonte: Elaboração própria.

$\psi$ : Período da gestão Tombini: $1^{\circ}$ Trimestre de 2011 ao $2^{\circ}$ Trimestre de 2016. Período da gestão Ilan Goldfajn: $3^{\circ}$ Trimestre de 2016 ao $4^{\circ}$ Trimestre de 2017.

Tabela 12: Resultados da estatística H por período de liderança no Banco Central $\psi$

\begin{tabular}{ll}
\hline Bancos - gestão Tombini & 0,5037 \\
Bancos - gestão Goldfajn & 0,7983 \\
Conglomerados - gestão Tombini & 0,3600 \\
Conglomerados - gestão Goldfajn & 0,4768 \\
\hline
\end{tabular}

Fonte: Elaboração própria.

$\psi$ : Período da gestão Tombini: $1^{\circ}$ Trimestre de 2011 ao $2^{\circ}$ Trimestre de 2016. Período da gestão Ilan Goldfajn: $3^{\circ}$ Trimestre de 2016 ao $4^{\circ}$ Trimestre de 2017. 
Ademais, a diferença entre as estatísticas $\mathrm{H}$ encontradas em cada período examinado é maior para os bancos $(0,2946)$ do que para os conglomerados $(0,1168)$. Isso sugere não apenas ter havido maior concorrência no setor bancário durante a gestão Goldfajn, mas também que o processo foi mais intenso quando se considera os bancos analisados por CNPJ.

\section{CONSIDERAÇÕES FINAIS}

Neste trabalho, buscou-se avaliar a evolução da concentração bancária no Brasil e verificar as características da concorrência na indústria bancária no país no período 2010- 2017. Os índices de concentração de mercado encontrados no período sugerem haver aumento da concentração do mercado bancário brasileiro com o passar dos anos. Isso vale tanto para os bancos para os conglomerados financeiros, só que de forma mais intensa neste último caso.

Os resultados do modelo Panzar \& Rosse alinham este estudo com os outros trabalhos sobre o tema. Assim como em outros trabalhos anteriores, manteve-se a indicação de que o mercado bancário doméstico opera em concorrência monopolística, também no caso dos bancos $(\mathrm{H}=0,5313)$ e dos conglomerados financeiros $(\mathrm{H}=0,4230)$.

Sobre os resultados para as estimações dos diferentes períodos de liderança do Banco Central, a primeira observação é de que a estatística $\mathrm{H}$ encontrada foi menor para os conglomerados financeiros do que para os bancos, tanto para a gestão de Tombini, quanto para a de Goldfajn. Essa diferença aponta para uma concorrência menor entre os conglomerados, tal como encontrado por Cardoso (2011).

Por outro lado, a análise comparativa indica que a estatística H no período Goldfajn se mostrou mais elevada do que na era Tombini, tanto na avaliação por CNPJ, quanto para a avaliação por conglomerados financeiros. Essa diferença positiva entre as estatísticas $\mathrm{H}$ dos dois períodos sugere haver maior concorrência entre os bancos e conglomerados financeiros no período em que Goldfajn foi o presidente do BC. Uma possível explicação para isso pode ser a queda na taxa Selic num contexto geral de inflação mais comportada no país na gestão Goldfajn, diferentemente do ocorrido no período em que Tombini liderava a autoridade monetária. Em outras palavras, a queda na taxa básica de juros doméstica pode ter estimulado a concorrência em um setor acostumado a trabalhar com juros altos e com altas taxas de lucros - obtidas muitas vezes pela simples aplicação em títulos da dívida pública.

Mesmo assim, cumpre ressaltar que, embora tenham caído ${ }^{18}$, os spreads ainda estão em patamares muito altos quando se considera o nível historicamente baixo da taxa básica de juros da economia brasileira. Isso tudo remete à discussão da necessidade ou não de se estabelecer políticas para intensificar a competição no mercado bancário brasileiro. Neste sentido, vale ressaltar o acordo assinado pelo Banco Central e o CADE em 28 de fevereiro de 2018, em que ambos se comprometeram a alinhar ações que estimulem a concorrência no setor bancário brasileiro, bem como a aprovação do Lei Complementar 166/2019, que altera as regras do chamado Cadastro Positivo. Futuros trabalhos podem ter como agenda específica a análise da eficácia dessas medidas para reduzir as taxas de juros para os tomadores finais de crédito no país.

\section{REFERÊNCIAS}

ARAÚJO, Luiz Alberto D.'Avila; JORGE NETO, Paulo de Melo; PONCE, David Agustın Salazar. Competição e concentração entre os bancos brasileiros. Revista Economia, 2006.

\footnotetext{
${ }^{18}$ Vide Figura 9, acima.
} 
BANCO CENTRAL DO BRASIL.... Vários Relatórios. Disponível em: <https://www4.bcb.gov.br/fis/cosif/balancetes.asp?frame=1>. Acesso 01 jan. 2019.

BELAISCH, A. Do Brazilian Banks Compete? In: IMF Working Paper, Washington, Fundo Monetário Internacional, 2003. Disponível em: <https://www.imf.org/external/pubs/ft/wp/2003/wp03113.pdf>. Acesso em: 02 dez. 2018.

BIKKER, Jacob A.; HAAF, Katharina. Measures of competition and concentration in the banking industry: a review of the literature. Economic \& Financial Modelling, v. 9, n. 2, p. 53-98, 2002.

BRADESCO conclui compra do HSBC Brasil e paga R \$ 16 bilhões. G1.globo.com, 16 jul. 2016. Disponível em: <http://g1.globo.com/economia/negocios/noticia/2016/07/bradesco-paga-r-16-bilhoes-econclui-compra-do-hsbc-brasil.html> Acesso em: 14 jan.2019.

CARDOSO, Marcelo J. R. Regulação, poder de mercado e concorrência dos bancos no brasil sob a avaliação dos conglomerados financeiros. 2011. Tese de doutorado - Escola de Economia de São Paulo, São Paulo, 2011.

CARVALHO, Fernando J. C. Estrutura e Padrões de Competição no Sistema Bancário Brasileiro: uma Hipótese para Investigação e Alguma Evidência Preliminar. In: OREIRO, José L.; PAULA, (orgs.). Sistema Financeiro: Uma análise do setor bancário brasileiro. Rio de Janeiro: Editora Elsevier, 2007. p. 221-251.

CASTOR, Kamaiaji de S. Estrutura de Mercado: Concentração e Concorrência no Sistema Bancário Brasileiro entre 2002 e 2012, 2013. Monografia de Bacharelado - Universidade Federal do Rio de Janeiro, Rio de Janeiro, 2013.

GOVERNO usa tripé para o país, diz secretário da Fazenda. O Globo, 14 ago. 2013. Disponível em: <https://oglobo.globo.com/economia/governo-usa-novo-tripe-para-pais-diz-secretario-dafazenda-9529316> Acesso em: 14 jan.2019.

\section{IBGE. SISTEMA NACIONAL DE ÍNDICES DE PREÇOS AO CONSUMIDOR IPCA E}

INPC ABRIL DE 2018. Rio de Janeiro: IBGE, 2018. Disponível em:

<ftp://ftp.ibge.gov.br/Precos_Indices_de_Precos_ao_Consumidor/IPCA/Fasciculo_Indicadores_I BGE/ipca-inpc_201804caderno.pdf.> Acesso em: 22 mai. 2019.

LEAL, Rodrigo M. Estrutura e determinantes do spread bancário no Brasil após 1994: uma análise da literatura empírica. In: OREIRO, José L.; PAULA, (orgs.). Sistema Financeiro: Uma análise do setor bancário brasileiro. Rio de Janeiro: Elsevier, 2007. p. 221-251.

LUCRO dos maiores bancos do Brasil cresce $17 \%$ no $2^{\circ}$ tri e soma R $\$ 16,8$ bilhões [2018]. Disponível em: <https://g1.globo.com/economia/noticia/2018/08/09/lucro-dos-maiores-bancosdo-brasil-cresce-17-no-2o-tri-e-soma-r-168-bilhoes.ghtml>. Acesso em: 08 jan. 2019.

MANTEGA, Guido. O primeiro ano da nova matriz econômica. Valor Econômico, São Paulo, 19 dez.2012. Disponível em: <http://www.valor.com.br/brasil/2945092/o-primeiro-ano-da-novamatriz-economica>. Acesso em: 25 jan. 2019.

MINISTÉRIO DA JUSTIÇA, CADE. Guia para a análise dos atos de concentração horizontal. Disponível em: <http://www.cade.gov.br/acesso-a-informacao/publicacoesinstitucionais/guias_do_Cade/guia-para-analise-de-atos-de-concentracao-horizontal.pdf >. Acesso em: 22 mai. 2019. 
NAKANE, Márcio I. A Test of Competition in Brazilian Banking. Working Papers Series, $\mathbf{n}$. 12, Banco Central do Brasil, 2001. Disponível em:

<https://www.bcb.gov.br/pec/wps/ingl/wps12.pdf>. Acesso em: 18 mai. 2018.

NAKANE, Márcio I.; ROCHA, Bruno. Concentração, concorrência e rentabilidade no setor bancário brasileiro: uma visão atualizada. Tendências Consultoria Integrada, BACEN, 2010.

NUNES, T.; MENEZES, G.; DIAS JR, P. Reavaliação da rentabilidade do setor bancário brasileiro: uma abordagem em dados em painel (2000-2012). In: Encontro de Economia da Região Sul, 16, 2013, Curitiba. Anais... Curitiba: ANPEC SUL, 2013.

PANZAR, J.C.; ROSSE, J.N. Testing for Monopoly Equilibrium. Journal of Industrial Economics, v. 35, p. 443-456, 1987.

PIRTOUSCHEG, Lívia A. S. Taxa básica de juros, competição bancária e spread nas operações de crédito para pessoas físicas no Brasil: uma análise teórica e empírica, 2014. Dissertação de Mestrado - Universidade Federal de Uberlândia, Uberlândia, 2014.

SILVEIRA, P. P. B. CONCENTRAÇÃO E COMPETIÇÃO BANCÁRIAS NO BRASIL Uma aplicação do Modelo Panzar-Rosse, 2017. Dissertação de Mestrado - Escola de Economia de São Paulo, São Paulo, 2017.

WOOLDRIDGE, Jeffrey M. Introductory Econometrics: A Modern Approach. 5. ed. Mason: Cengage Learning, 2012. 